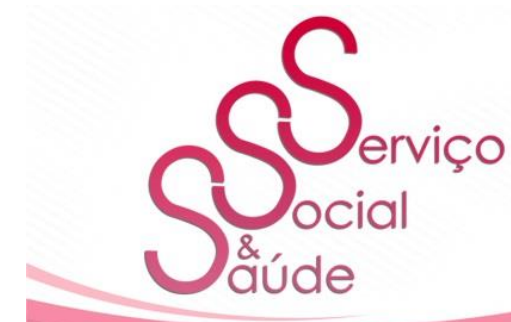

ISSN 2446-5992

(요요

doi: 10.20396/sss.v19i0.8661082

\title{
A participação da família no processo de cuidado \\ da criança hospitalizada
}

Family participation in the hospitalized child care process

\author{
Meirielle Soares de Menezes ${ }^{1}$ \\ Ingrid Bezerra Costa Maia ${ }^{2}$
}

\section{RESUMO}

O adoecimento e a hospitalização de uma criança trazem inúmeras mudanças e requer um grande suporte familiar, pois esta é considerada essencial e apresenta significativa influência durante esse período. Com isso, o presente estudo teve como objetivo analisar a participação da família no processo de cuidado da criança hospitalizada. Para realizá-lo foi utilizado uma abordagem qualitativa, com oito entrevistas semiestruturadas, aplicadas na unidade de pediatria do Hospital de Messejana Dr. Carlos Alberto Studart Gomes - HM, em Fortaleza - Ceará. A coleta de dados ocorreu entre julho a outubro de 2019. Após transcritos, os dados foram analisados e discutidos. Definiram-se três categorias de análise: Mulheres Cuidadoras; Rede de apoio familiar e A importância da família no processo de cuidado. A análise mostrou que as mulheres são as principais cuidadoras das crianças, corroborando para a discussão das relações de gênero e seus desdobramentos. Destarte, conclui-se a necessidade do fortalecimento do vínculo familiar, visto a importância da participação da família durante a hospitalização e a criação de políticas públicas voltadas para ampliação da autonomia das mulheres.

Palavras-chave: Família, Gênero, Hospitalização.

\section{ABSTRACT}

A child's illness and hospitalization bring many changes and require great family support, as this is considered essential and has a significant influence during this period. Thus, the present study aimed to analyze the family's participation in the care process of hospitalized children. To do this, a

\footnotetext{
${ }^{1}$ Assistente Social, Residente em Cardiopneumologia pela Escola de Saúde Pública do Ceará, ESP/CE.

Telefone: 5585 986724241. E-mail: meiriellesoares1@ hotmail.com.

${ }^{2}$ Assistente Social, Mestre em Saúde da Família pela Universidade Estadual do Ceará, UECE. Email: costauece@gmail.com.
}

\begin{tabular}{l|l|l|l|l|l}
\hline Serv. Soc. \& Saúde & Campinas, SP & v. 19 & $1-20$ & e020005 & e-ISSN 2446-5992 \\
\hline
\end{tabular}




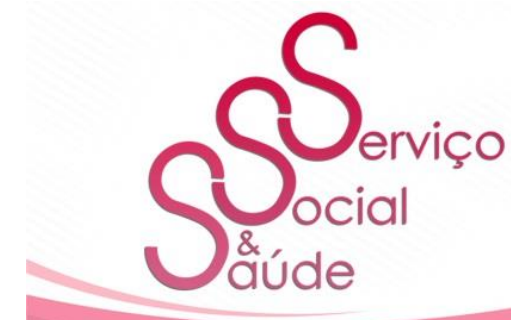

ISSN 2446-5992

(c) (1)(2)

doi: $10.20396 /$ sss.v19i0.8661082

qualitative approach was used, with eight semi-structured interviews, applied at the pediatric unit of the Hospital de Messejana Dr. Carlos Alberto Studart Gomes - HM, in Fortaleza - Ceará. Data collection took place between July and October 2019. After transcription, the data were analyzed and discussed. Three categories of analysis were defined: Women Caregivers; Family support network and The importance of the family in the care process. The analysis showed that women are the main caregivers of children, corroborating the discussion of gender relations and their consequences. Thus, we conclude the need to strengthen the family bond, given the importance of family participation during hospitalization and the creation of public policies aimed at expanding women's autonomy.

KEYWORDS: Family. Gender. Hospitalization.

\section{INTRODUÇÃO}

O presente estudo busca contribuir com as pesquisas que investigam a atuação da família durante o tratamento das crianças hospitalizadas, visto que são poucos materiais do Serviço Social relacionados à temática. Tal análise foi possível a partir da atuação enquanto residente multiprofissional em um hospital terciário.

A Residência Integrada em Saúde (RIS), instituída pela Escola de Saúde Pública do Ceará (ESP-CE) foi concebida em 2011/2012, inaugurada em 2013, e visa o desenvolvimento do saber (conhecimentos), do fazer (habilidades) e do ser (atitudes) dos residentes, possibilitando transformar as práticas profissionais. Essa formação segue a perspectiva da integralidade da atenção, tendo como referência os princípios do Sistema Único de Saúde (SUS) e a atuação interprofissional, respeitando e fortalecendo os saberes de cada profissão (ESP, 2019).

Tendo em vista as habilidades que a formação da RIS proporciona, o assistente social residente se insere no cenário de prática com uma escuta ativa e o acolhimento como ações essenciais em todo o percurso. Assim, durante a escuta e a observação, foi identificada a importância da família no processo de hospitalização das crianças.

A aproximação com o objeto de pesquisa se deu a partir da atuação na Residência Multiprofissional em Saúde realizada durante o rodízio na Unidade de Pediatria do Hospital 


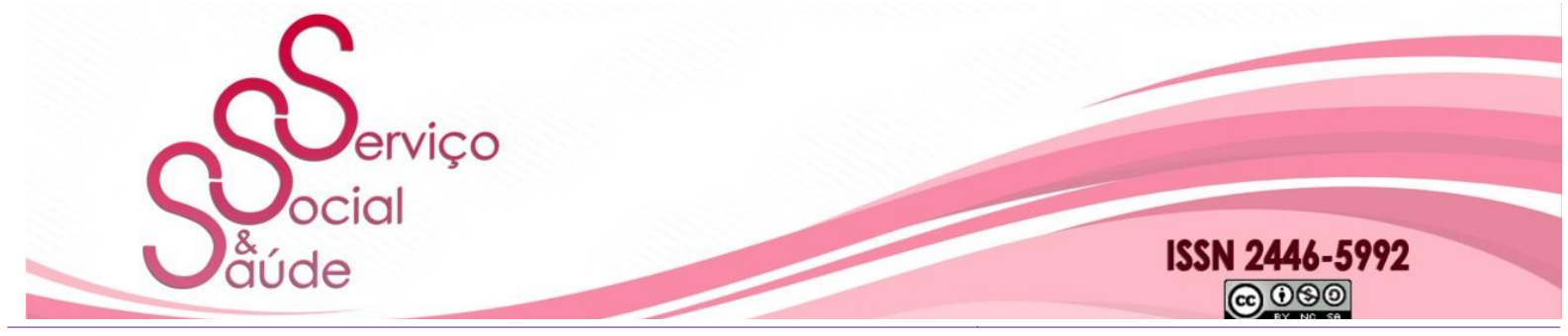

doi: 10.20396/sss.v19i0.8661082

de Messejana Dr. Carlos Alberto Studart Gomes - HM, quando foi possível perceber o quão é significativa a participação da família durante o processo de tratamento da criança hospitalizada. O interesse pelo estudo da temática se tornou maior, ao perceber que, em muitos casos, apenas um sujeito participa ativamente como cuidador direto. De acordo com uma pesquisa realizada em 2014 para analisar o envolvimento dos pais no cuidado das crianças hospitalizados, foi observado que, em relação aos acompanhantes, $82 \%$ são as mães das crianças internadas, $17 \%$ pais e apenas $1 \%$ composto de outros cuidadores (MELO et al, 2014).

A hospitalização de uma criança traz consigo muitas mudanças na dinâmica familiar e requer novas formas de organização para o enfrentamento do período de internação. Tal situação é crítica para toda a família, além da mudança do ambiente físico, há a separação dos membros familiares, sentimento de medo e interrupção das atividades cotidianas. Nesse momento, o suporte familiar e sua participação se torna fundamental no processo de tomada de decisões e prestação de cuidados, podendo minimizar tais mudanças (ANJOS, 2015).

Para entender o sujeito e suas ações, é necessário nos basearmos no indivíduo cuidador, pois seus valores, atitudes e comportamentos no cotidiano expressam constantemente a preocupação com o indivíduo hospitalizado. Nesse sentido, o cuidar é considerado uma dimensão ontológica do ser humano e uma forma de "ser-no-mundo". Assim, o cuidar implica não apenas uma função, tarefa ou atividade, mas possui valor substantivo que traz em si uma alteridade que envolve respeito, sacralidade, reciprocidade e complementaridade.

Este ato é comum a todas as culturas, embora suas formas de expressão possam ser as mais variadas. Se buscarmos um ponto em comum a todos os povos, quanto ao contexto em que ocorre o cuidar, verificaremos que este parece ser a família. Esta instituição é quem tem se colocado de forma mais efetiva para executar o cuidado, ou quando não o faz diretamente, repassa a tarefa a outro agente social, diante da dificuldade e/ou impossibilidade de fazê-lo (MAFRA, 2011). 


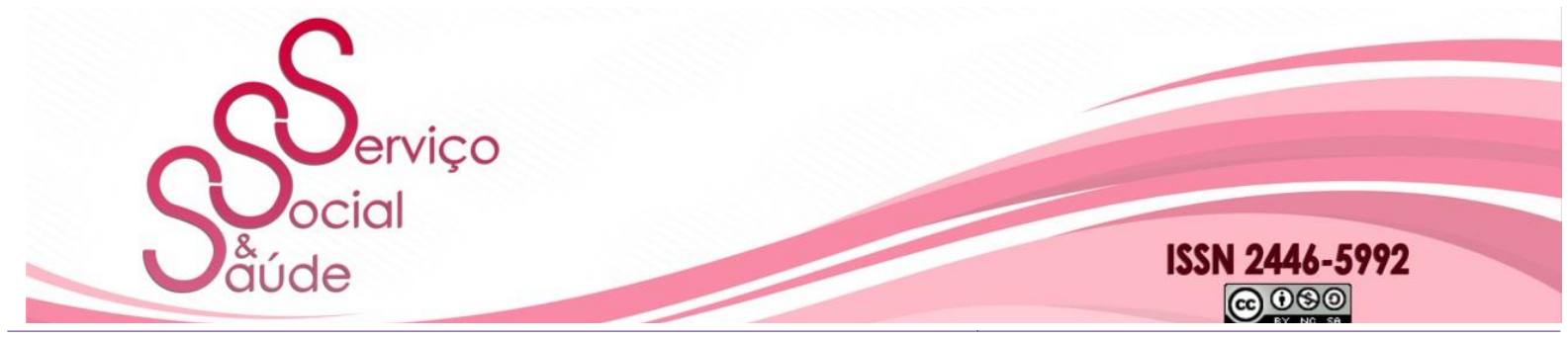

doi: 10.20396/sss.v19i0.8661082

Independente da configuração familiar, o vínculo entre os indivíduos é de extrema importância, sendo fator essencial para o desenvolvimento do sujeito em todos os âmbitos, especialmente quando se trata de questões relacionadas à saúde. Entende-se que é preciso compreender também se os familiares participam do cuidado relacionado a saúde do sujeito hospitalizado, revezando, dividindo a atribuição do cuidar, ou se apenas um ou dois indivíduos exercem esse papel que deriva do ato de cuidar.

Segundo Mioto (2010), a família, nas suas mais diversas configurações constitui-se como um espaço altamente complexo. É construída e reconstruída histórica e cotidianamente, através das relações e negociações que estabelece entre seus membros e outras esferas da sociedade, tais como Estado, trabalho e mercado. Reconhece-se também que além de sua capacidade de produção de subjetividades, ela é uma unidade de cuidado.

Com isso, a concepção de família tratada aqui não se refere apenas aquela com papéis predefinidos (casal e filhos), tomada por muitos como a ideal, mas a família ampliada e extensa definida no art. 25 do Estatuto da Criança e do Adolescente - ECA como aquela que se estende para além da unidade pais e filhos ou da unidade do casal(BRASIL, 1990).

Apesar de compreender que a família não é a única responsável pelo bem-estar do sujeito, sua participação, em qualquer fase da vida, é de fundamental importância, principalmente ao nascer, em que sua situação de dependência é extrema, precisando de cuidados para manter-se vivo. Estudos apontam a importância da presença dos pais na UTI Neonatal (UTIN) e da participação deles nos cuidados ao filho hospitalizado, não apenas para o estabelecimento do vínculo afetivo, mas também para a redução do estresse causado pela hospitalização e no preparo para o cuidado à saúde no domicílio (GAÍVA; SCOCHI, 2005).

Sabe-se que o modelo tradicional de assistência centrado na criança doente vem mudando e abrindo espaço para um novo modelo que permite a presença dos pais e a incorporação da família no cuidado. Porém, mesmo com as mudanças ocorridas, é necessário compreender se a família participa ativamente desse cuidado, quem são os sujeitos 


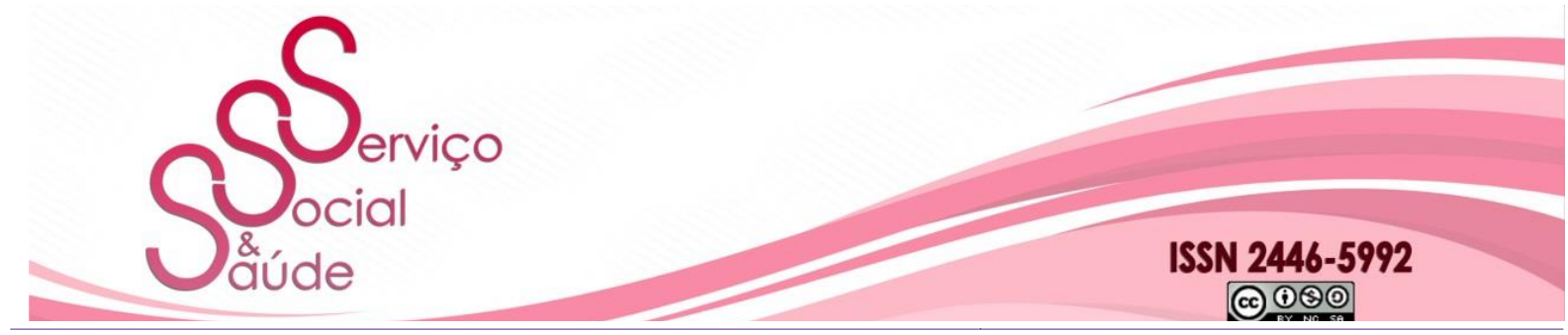

doi: 10.20396/sss.v19i0.8661082

participantes que dispõem de tempo, e se desgastam fisicamente e emocionalmente para garantir atenção integral ao familiar que necessita de cuidado.

É preciso entrar no cerne da questão para compreender quem são os protagonistas do cuidado, o papel e a importância da família durante esse processo e se a função protetiva da família está sendo desempenhada de forma integral durante o período de hospitalização da criança.

A partir dessa perspectiva, o presente estudo objetivou analisar a participação da família no processo de cuidado da criança hospitalizada. Além de apreender pela fala dos entrevistados a sua compreensão sobre família; conhecer a realidade das crianças internadas no Hospital de Messejana e identificar os familiares que participam ativamente no processo de cuidado e tratamento da criança.

\section{METODOLOGIA}

Segundo José Filho (2006, p. 64) "o ato de pesquisar traz em si a necessidade do diálogo com a realidade a qual se pretende investigar e com o diferente, um diálogo dotado de crítica, canalizador de momentos criativos”. Assim, para a tentativa de conhecer qualquer fenômeno da realidade, deve-se buscar uma aproximação desta, visto sua intensa complexidade e dinamicidade dialética. Porém, a pesquisa não é um ato isolado, e como não existe pesquisa sem o apoio de técnicas e instrumentos metodológicos, as técnicas utilizadas no estudo para a obtenção de dados são de natureza qualitativa.

O caráter qualitativo é traduzido por aquilo que não pode ser mensurável, pois a realidade e o sujeito são elementos indissociáveis. Quando se trata do sujeito, levam-se em consideração seus traços subjetivos e suas particularidades. Tais pormenores não podem ser traduzidos em números quantificáveis. Segundo Minayo (2014), a pesquisa qualitativa trabalha com o universo de significados, motivos, aspirações, crenças, valores e atitudes, o que corresponde a um espaço mais profundo das relações, dos processos e dos fenômenos que 


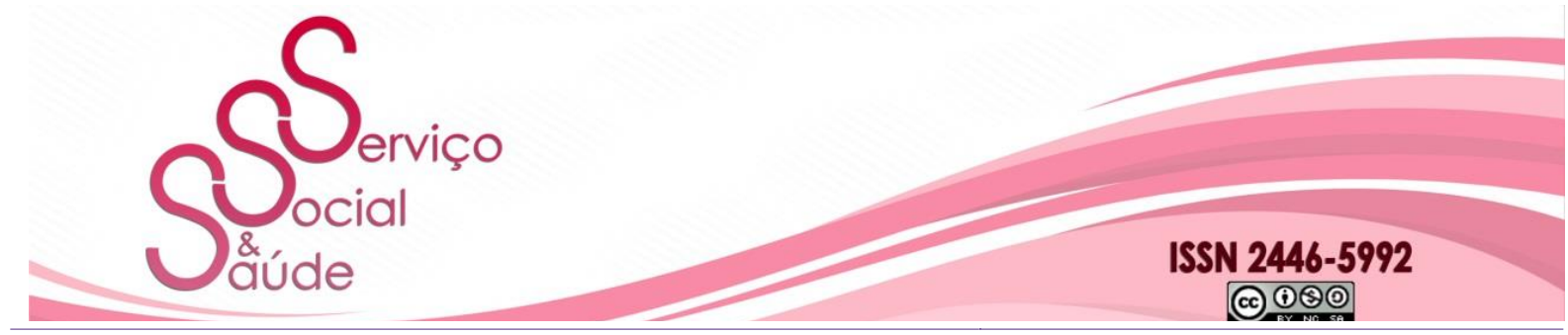

doi: $10.20396 /$ sss.v19i0.8661082

não podem ser reduzidos à operacionalização de variáveis. Dessa forma, para colher tais dados, a pesquisa foi de caráter qualitativo, estimulando os entrevistados, a pensar e falar livremente sobre o tema abordado. É na pesquisa qualitativa que se fazem emergir aspectos subjetivos, atingem motivações não explícitas, ou mesmo não conscientes, de forma espontânea.

A pesquisa social, para Minayo (2015), não pode almejar o alcance da objetividade em seus resultados, no entanto pode chegar à objetivação, ou seja, uma aproximação o mais fiel possível da realidade, mas que não atinge todos os seus complexos. Conhecer esse objeto histórico ao qual se destina a investigação social implica conhecer o processo histórico que o formou, e não só, a conjuntura em que se encontra no momento da pesquisa.

Neste trabalho foi usada a pesquisa de campo para o estudo de indivíduos, grupos, comunidades e instituições, com o objetivo de compreender os mais diferentes aspectos de uma determinada realidade.

\subsection{Percurso Metodológico}

Quando nos debruçamos sobre a pesquisa, seja em qualquer área, sabemos das inúmeras possibilidades que encontraremos no percurso, dessa forma, as etapas da pesquisa foram planejadas e seguidas de acordo com o programado para o êxito da pesquisa. A coleta de dados ocorreu entre julho a outubro de 2019, nas enfermarias ou na parte externa da pediatria. Para a coleta de dados foram utilizadas técnicas para dar início a pesquisa:

a) Apresentação da pesquisa aos entrevistados

Nesse momento, ao ser identificado o potencial participante, foi explicitado de forma objetiva e de fácil compreensão sobre a pesquisa e, em seguida, feita a pergunta sobre o interesse do acompanhante em participar, com a resposta positiva em participar da pesquisa, o entrevistado assinou o termo de consentimento livre e esclarecido - TCLE. 


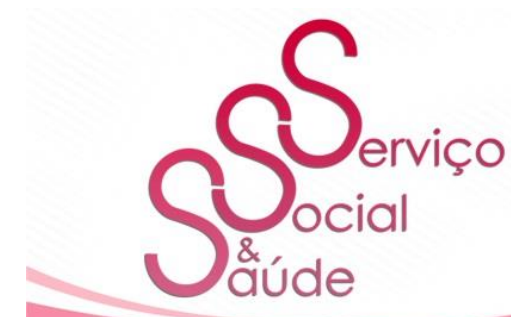

ISSN 2446-5992

(๑) $\odot \odot \odot$

doi: 10.20396/sss.v19i0.8661082

b) Entrevista semiestruturada

A entrevista foi realizada em local silencioso, buscando inicialmente traçar o perfil sócio demográfico do entrevistado e, em seguida, feitas as perguntas orientadoras da pesquisa que constam no roteiro. O diálogo foi gravado, previamente autorizado pela assinatura do TCLE.

c) Observação e Diário de Campo

Foram feitas anotações diárias ao ser observadas atitudes, comportamentos ou expressões dos entrevistados relacionados ao tema da pesquisa ou registros que sejam considerados necessários e que não foram percebidos nas respostas dos entrevistados.

\subsection{Instrumentos e Técnicas}

Foi realizada a pesquisa de campo em que há a observação de fatos e fenômenos exatamente como ocorrem no real, coleta de dados, análise e a interpretação desses dados, com base numa fundamentação teórica, com o objetivo de compreender e explicar o problema pesquisado.

Utilizou-se a entrevista que segundo Gil (2008) pode-se definir como uma técnica em que o investigador se apresenta frente ao investigado e lhe formula perguntas, com o objetivo de obtenção dos dados que interessam à investigação. A entrevista é, portanto, uma forma de interação social. Mais especificamente, é uma forma de diálogo assimétrico, em que uma das partes busca coletar dados e a outra se apresenta como fonte de informação. A pesquisa de caráter qualitativo utilizou a técnica de entrevista (semi estruturada), em que o entrevistado é deixado para decidir-se sobre a sua resposta.

Uma próxima técnica foi o diário de campo que se caracteriza por ser um instrumento de registro diário, também pode-se dizer que ele é uma parte das técnicas de pesquisa. Minayo (2015) refere que no diário de campo constam todas as informações que não sejam o registro das entrevistas formais. Ou seja, observações sobre conversas informais, comportamentos, 


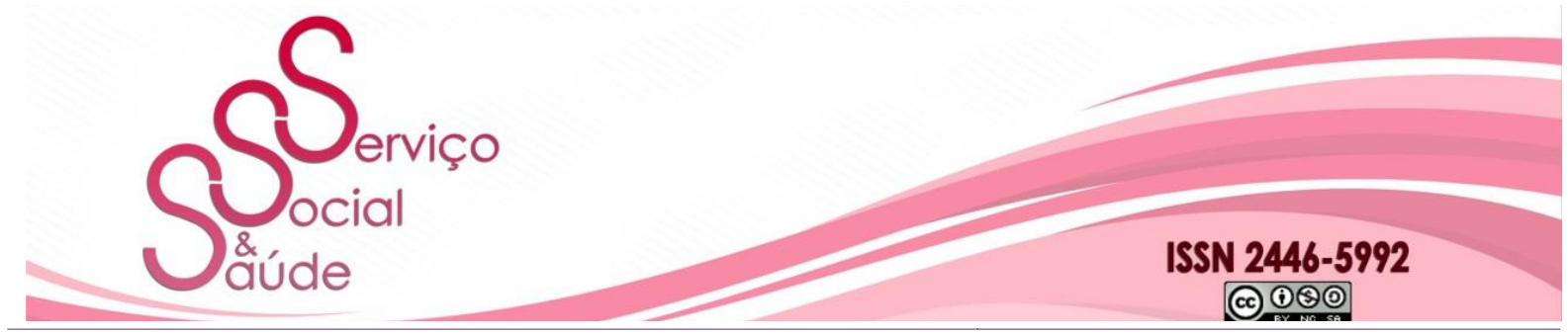

doi: 10.20396/sss.v19i0.8661082

8

cerimoniais, festas, instituições, gestos, expressões que digam respeito ao tema da pesquisa, falas, comportamentos, hábitos, usos, costumes, celebrações e instituições compõem o quadro das representações sociais.

A observação também é um importante meio para a coleta de dados, capaz de complementar as informações obtidas durante a pesquisa, uma vez que alguns aspectos da realidade apresentada ficam evidenciados nas atitudes dos sujeitos no momento da entrevista e não nas suas respostas. Barros \& Lehfeld (2000) afirmam que a observação como uma das técnicas de coleta de dados é imprescindível em toda pesquisa científica. Observar significa aplicar o sentido a um objeto para adquirir um conhecimento claro e preciso dele, pois, é da observação do cotidiano que se formula problemas que merecem estudo.

Para analisar os dados colhidos no campo, realizou-se a metodologia da análise do discurso, que é um método cujo objetivo é não somente compreender uma mensagem, mas reconhecer qual é o seu sentido, ou seja, o seu valor e sua dependência com um determinado contexto. Putnam e Fairhurst (2001) definem análise do discurso como sendo o estudo de palavras e expressões: tanto a forma quanto o uso no contexto, além dos significados ou interpretações de práticas discursivas. Tais instrumentos foram utilizados por serem os mais indicados para compreender o objeto estudado.

\subsection{Campo de Pesquisa}

A pesquisa foi desenvolvida no Hospital de Messejana Dr. Carlos Alberto Studart Gomes - HM, que compõe a rede da Secretaria de Saúde do Estado do Ceará oferecendo serviços de alta complexidade, e funcionando como local de referência Norte e Nordeste em relação a doenças cardíacas e pulmonares. Principal destino de adultos e crianças com doenças cardíacas e, com problemas pulmonares multirresistentes.

O HM tem 262 leitos de internação, divididos em sete unidades de internação: duas unidades de Pneumologia (H e J) e quatro unidades de cardiologia (Pediatria, B, C, G e I). 


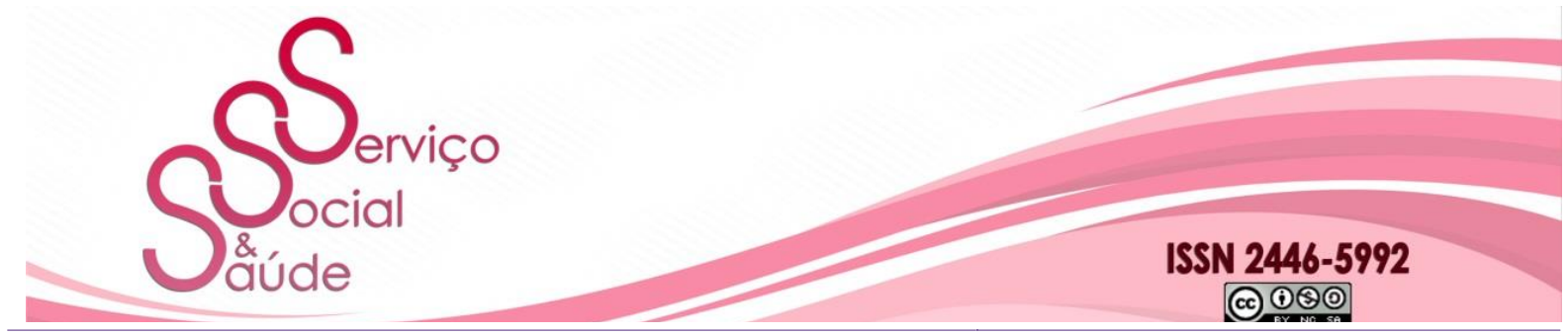

doi: 10.20396/sss.v19i0.8661082

Conta ainda com 47 leitos de Unidades de Terapia Intensiva (UTI), sendo elas: UTI cardiopulmonar, respiratória, coronariana, pediátrica clínica, pós-operatório infantil, pósoperatório adulto e unidade semi-intensiva com 14 leitos.

A pesquisa foi realizada na enfermaria da unidade de pediatria do HM, um dos locais de lotação dos residentes multiprofissionais da ênfase de cardiopneumologia.

\subsection{Participantes}

Os participantes desta pesquisa foram os familiares/acompanhantes dos pacientes pediátricos internados no Hospital de Messejana Dr. Carlos Alberto Studart Gomes - HM. Tendo como critério de inclusão, crianças internadas na enfermaria da unidade de pediatria há no mínimo um mês. Já como critério de exclusão, foi o de crianças que iriam se submeter a cirurgia no dia da coleta de dados, visto que os familiares estão extremamente fragilizados durante esse momento.

Em relação ao quantitativo de participantes, é importante ressaltar que a pesquisa objetivou pela saturação das respostas como um fator importante para o encerramento do estudo.

$\mathrm{Na}$ pesquisa, foi possível apreender que todas as participantes são do sexo feminino, sendo que sete delas são mães das crianças hospitalizadas e uma delas irmã da criança. A faixa etária varia de 19 a 56 anos, quatro delas são casadas; duas têm união estável; e duas são solteiras. Em relação à naturalidade, apenas uma é de Fortaleza, as outras são de municípios do interior do Estado do Ceará. A renda familiar de sete entrevistadas é de apenas um salário mínimo, e uma refere a renda ser de dois salários mínimos.

No que tange a questão do acesso a benefícios socioassistenciais, constatou-se que das oito participantes, apenas duas não recebem nenhum tipo de benefício oriundo da Assistência Social, sendo quatro beneficiárias do Benefício de Prestação Continuada e duas do Programa Bolsa Família. Sobre a escolaridade, apenas uma teve acesso ao ensino superior (incompleto);

\begin{tabular}{l|l|l|l|l|l}
\hline Serv. Soc. \& Saúde & Campinas, SP & v. 19 & $1-20$ & e020005 & e-ISSN 2446-5992 \\
\hline
\end{tabular}




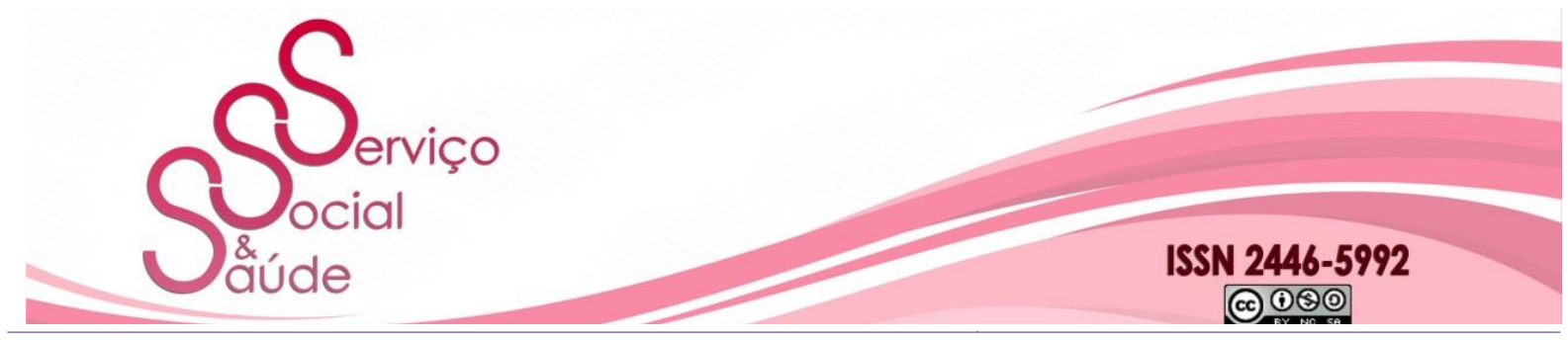

doi: 10.20396/sss.v19i0.8661082

três concluíram o ensino médio; uma o ensino médio incompleto; duas o ensino fundamental incompleto e uma não possui escolaridade. Outro aspecto que deve ser ressaltado consiste no fato que das oito participantes, quatro delas declararam ter uma profissão, uma respondeu ser agricultora; uma vendedora; uma empregada doméstica; e uma atendente, mas nenhuma está exercendo atualmente, devido à necessidade do cuidado integral à criança.

\subsection{Aspectos Éticos}

A pesquisa teve por base a Resolução 466/ 2012 do Ministério da Saúde que prevê a proteção devida aos participantes das pesquisas científicas envolvendo seres humanos, assim, o estudo foi previamente submetido à aprovação pela Plataforma Brasil.

Durante a pesquisa utilizou-se instrumento para coleta de dados (Apêndice A) e o termo de consentimento livre e esclarecido - TCLE, que é um documento em que informa e esclarece o sujeito da pesquisa de maneira que ele possa tomar sua decisão de forma justa e sem constrangimentos sobre a sua participação na pesquisa. $O$ termo foi escrito com linguagem acessível para que seja garantido que o pesquisado tenha tido clareza do que foi realizado. Tal documento é uma proteção legal tanto para o pesquisador quanto para o pesquisado, pois ambos estiveram assumindo responsabilidades. O Comitê de Ética e Pesquisa do HM emitiu parecer consubstanciado sob n. 3.394 .988 aprovando o presente estudo em 17 de junho de 2019.

\section{RESULTADOS E DISCUSSÕES}

A apresentação e a discussão dos resultados foram organizadas em consonância com as categorias que se evidenciaram durante o estudo: Mulheres cuidadoras; Rede de apoio familiar e a importância da família no processo de cuidado. 


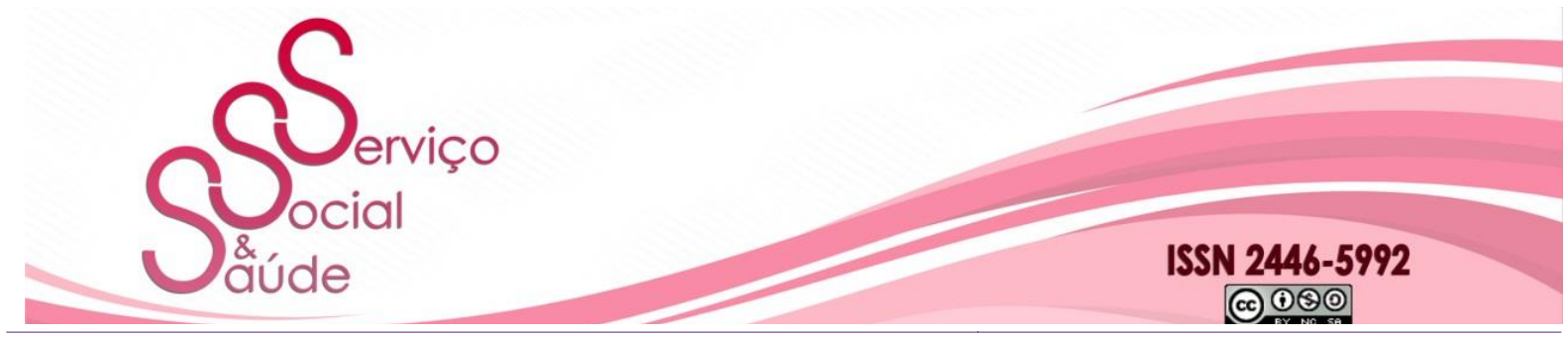

doi: $10.20396 /$ sss.v19i0.8661082

\subsection{Mulheres cuidadoras}

Para alcançar os objetivos da presente pesquisa, foi necessário entrevistar as acompanhantes das crianças internadas e questionar quem são os principais cuidadores durante a hospitalização da criança, visto que é um período desgastante, de cansaço extremo e a maioria das crianças passam meses internadas.

Sou eu quem cuido dela de tudo, de tudo, 24h ela tá comigo. Internada desde o dia 18 de julho. Só eu fico com ela. Ela mama, né? Só sou eu mesmo que cuido dela. (E1)

Sou eu. Sempre é eu, né? Tudo assim, viagem só sou eu. Eu ando mais é só. Não tenho ajuda de ninguém não. Tem as tias dele, né? Mas elas têm as coisas delas, a casa delas pra ajeitar. E é longe de lá pra cá, então sempre sou eu. (E2)

É eu mesmo. Só eu mesmo. Tem outra pessoa não... (E3)

Eu, né? Eu que fico aqui sempre. O pai é muito presente também, a família toda, meu pai, minha mãe, avó paterna, a família dela é muito presente. [...] Todo mundo quer vir ver direto. (E4)

Após traçar o perfil das participantes interlocutoras da pesquisa, identificou-se que as mães são as principais ou únicas cuidadoras dos filhos. Apenas uma entrevistada não é mãe, porém, nos informou que sua genitora faleceu e ela ficou responsável pelo cuidado com o irmão. Ou seja, somente mulheres acompanhavam as crianças hospitalizadas durante a coleta de dados. Apesar da legislação (lei. 8.069/90) garantir a permanência de acompanhante, independentemente do sexo, durante o período de hospitalização, ao longo da coleta de dados, estiveram presentes apenas mulheres.

Dados do relatório "Tempo de cuidar" da ONG Oxfam, publicado em 2020, corroboram para o estudo, pois mostram que as mulheres realizam mais de $75 \%$ de todo o trabalho de cuidado não remunerado do mundo e, frequentemente, segundo os dados do relatório da Oxfam, “elas trabalham menos horas em seus empregos ou têm que abandoná-los 


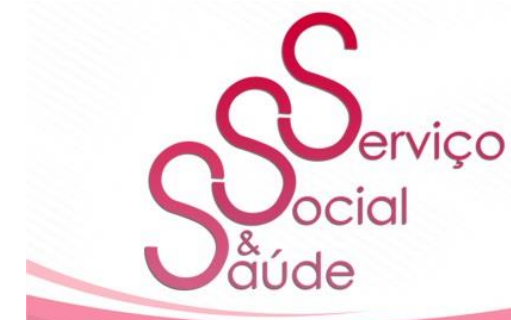

ISSN 2446-5992

(요요

doi: 10.20396/sss.v19i0.8661082

por causa da carga horária com o cuidado. Em todo mundo, $42 \%$ das mulheres não conseguem um emprego porque são responsáveis por todo o trabalho de cuidado - entre os homens, esse percentual é de apenas $6 \%$ ".

O maior número de cuidadores do sexo feminino no acompanhamento as crianças hospitalizadas, também foi confirmada no estudo de Jorge (2004). A autora ressalta que culturalmente, continua, ainda, a ser atribuído um maior peso de responsabilidade à mulher, relativamente ao acompanhamento da criança nos momentos em que esta necessita de mais cuidados, particularmente nos períodos de doença. Com isso, percebe-se que o papel da mulher como cuidadora mantém-se na contemporaneidade, inclusive durante a hospitalização da criança em que os cuidados são mais intensos.

Assim, observa-se, no geral, discursos em que a naturalização da mulher como cuidadora vincula-se a diferentes lugares atribuídos a ela na família: esposa ou companheira, filha, mãe, tia, avó. Desde que seja mulher, cuidar do membro da família que está adoecido e requer atenção constante ou ainda, cuidar dos familiares para que atravessem uma fase de fragilidade a fim de preservar o direito à vida torna-se prioritário sobre os próprios projetos. Ao identificar-se com o ato de cuidar, a mulher, muitas vezes, se afasta da possibilidade de outras escolhas, ou distancia-se dos próprios projetos. Cuidar do outro torna-se o seu cotidiano (GUEDES; DAROS, 2009).

Ele não mora mais eu, né? Ele mora com a minha mãe. Aí aqui no hospital fui eu que fiquei com ele. Aí agora quando ele sair do hospital quem vai ficar mais ele é a prima dele. No hospital quem ficou foi só eu e ela (tia), mas pro final quem ficou foi só eu. Acho que tô aqui há três meses com ele. Só eu. Mês passado que eu fui em casa, aí minha irmã ficou com ele cinco dias. (E7)

Percebe-se que quando a mãe não pode ficar com a criança ou precisa ir em seu domicílio resolver algo ou descansar, quem fica são outras mulheres, tias, primas ou avós. Não é pensado no homem para assumir este papel de cuidador, mostrando o quanto está enraizado o papel que ao longo dos anos foi atribuído à mulher. Segundo Guedes e Daros (2009) no senso moral construído na sociabilidade burguesa, as atividades que derivam do ato \begin{tabular}{|l|l|l|l|l|l|}
\hline Serv. Soc. \& Saúde & Campinas, SP & v. 19 & $1-20$ & e020005 & e-ISSN 2446-5992 \\
\hline
\end{tabular} 


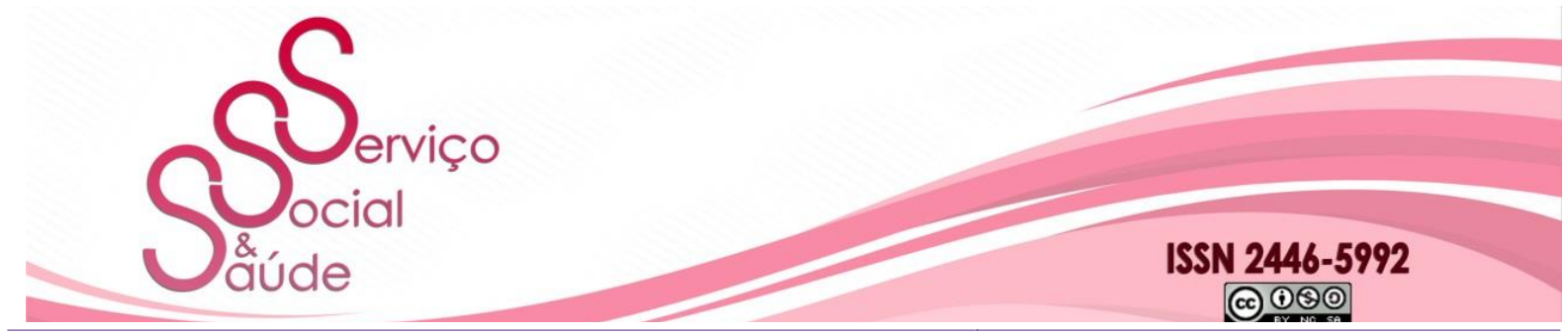

doi: 10.20396/sss.v19i0.8661082

de cuidar tendem a ser atribuídas às mulheres e naturalizadas de forma a aparecerem como exclusivas e constitutivas da condição feminina.

Quem acompanhou desde que nasceu foi o pai, porque eu fiz cesariana, daí depois de 15 dias eu vim ficar com ele. Desde então sou eu que tô com ele. O pai vem só na hora da visita, até porque tem que trocar fralda, né? E ele não sabe essas coisas... (E8)

É visível um discurso dominante advindo do contexto sociocultural de que a mulher tem esse papel central do cuidado e que o homem não tem jeito para cuidar de criança, reforçando que o cuidar é parte integrante apenas do universo feminino. No âmbito familiar, sociedade e cultura se entrelaçam sustentando a ideologia em nosso meio de que a mulher é a provedora dos cuidados às crianças, sobretudo quando o filho possui uma necessidade maior, levando-a a se dedicar, na maioria das vezes, integralmente ao cuidado do filho (ALVES; COSTA, 2014)

Pode-se apreender pelas falas das participantes uma forte influência cultural, em que o significado de ser mulher está ligado às características atribuídas ao ser mãe/cuidadora, o que reforça as relações desiguais de sexo e a divisão sexual do trabalho, reafirmando a concretude do patriarcado na vida das entrevistadas. A elas é destinado o cuidado e a responsabilidade integral com os filhos. Sobre elas recai o peso dessa responsabilidade não só no sentido de terem que executar atividades práticas de cuidado, mas principalmente porque se espera delas tal compromisso.

\subsection{Rede de apoio familiar}

Possuir uma rede disponível para auxiliar na superação de crises que ocorrem ao longo da vida é fator de proteção para o desenvolvimento dos membros da família. Assim, visto que a necessidade de apoio aumenta em determinadas circunstâncias e fases da vida, principalmente em casos de doença, a importância da presença dos pais e familiares durante esse momento da hospitalização, é essencial. 


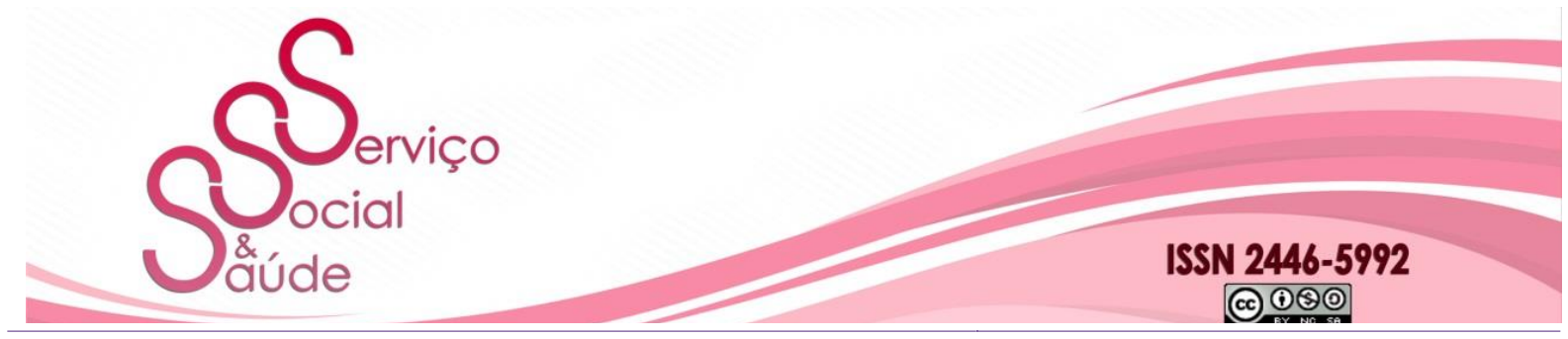

doi: 10.20396/sss.v19i0.8661082

Diante disso, foi perguntado para as acompanhantes sobre a participação da família durante esse processo, seja troca de acompanhante ou visitas e, apesar de tal presença e participação ser considerada essencial na assistência à criança hospitalizada, a partir das falas, percebeu-se que apenas uma pessoa participa efetivamente desse processo, focalizando na relação mãe-filho.

Não. Nunca fez troca de acompanhante. Eu nem vou em casa.

Veio só o pai. O pai não mora comigo não. Porque assim, ele mora lá (interior), é meio longe, sabe? Aí veio ver ele, só ele mesmo... veio só uma vez. Assim, eu converso com ele, ele me ajuda pra me deixar no hospital. Eu acho assim, que eles deviam participar mais. (E2)

Trocou uma vez de acompanhante... meu menino veio passar uma semana. Tem uma irmã que mora ali que veio visitar, minha menina também. (E3)

Percebe-se que é comum nas famílias um único membro assumir a maior parte da responsabilidade do cuidado, neste caso, a mulher. Ao tornar-se mãe e assumir para si a reponsabilidade pelo cuidado da criança, muitas rompem seus vínculos com o trabalho para dedicarem-se integralmente ao cuidado da criança. A divisão de tarefas não é realizada e ocorre seu acúmulo, afetando à vida financeira, profissional e familiar da mulher, que chega a renunciar seus projetos e realizações pessoais em função da criança. As desigualdades de gênero e a desigualdade das distribuições das tarefas condicionam a realidade do cuidado familiar.

Minhas irmãs moram perto de mim, me ajudam. A família dele também é muito louca por ela, eles só não vem porque moram no montese, mas quando a gente vai pra lá é um grude, eu mal pego nela. (E1)

Não. Até porque eles são do interior... eu não tenho familiar em Fortaleza, sou só eu e meu pai. Então não tem visita não... faz uns três meses, por aí... (E5)

Vale lembrar que essas pessoas já estão há mais de um mês acompanhando a criança hospitalizada e algumas nunca receberam visitas ou realizaram a troca de acompanhante. $\mathrm{O}$ que se objetiva aqui não é a culpabilização da família, e a retirada da responsabilidade do Estado, mas é necessária discussão que perpassa as questões de gênero, pois o cuidado pode 


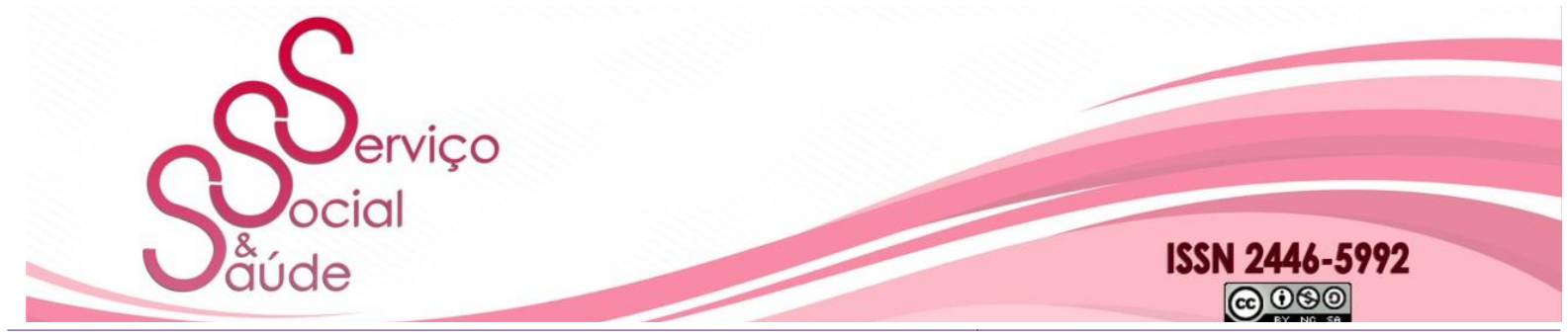

doi: 10.20396/sss.v19i0.8661082

ser realizado por mais de uma pessoa e todos são capazes de exercê-lo, no entanto, a maior parte das tarefas relacionadas ao cuidar é realizada normalmente por uma mulher, recaindo a responsabilidade unicamente sob ela.

\section{[...] o pai dela veio uma vez. (E6)}

Não. Veio visitar, mas foi duas ou três vezes. Foi só três vezes que o pai dele veio. E o tio dele, irmão do pai dele. (E7)

Depois que ele veio pra enfermaria, veio um primo e dois tios visitar ele. Como a família é do interior, não se organizou ainda pra vir visitar. (E8)

A partir dos relatos das entrevistadas, percebe-se que em relação ao número de pessoas que compõe a rede familiar parece ser grande, porém, identifica-se também a predominância de uma rede mínima quando se trata do cuidado com da criança, em que muitas vezes a distância geográfica é apontada como barreira.

Além disso, a mãe é vista como o principal vínculo e apoio social para a criança crescer e se desenvolver de forma saudável. Pelo menos é assim que a família define a função materna e é assim também que a mãe percebe seu próprio papel e funções predominantes dentro da família. Com base nisso, os demais membros da família assumem uma posição intermediária ou periférica na rede de cuidados e promoção do desenvolvimento da criança, com contatos menos frequentes, relacionamentos e vínculos de menor intensidade e menor compromisso e responsabilidade com o bem-estar da criança. (SILVEIRA et al., 2016)

Para Silveira et al. (2016) as redes de pequeno porte ou mínimas são menos efetivas em situações de excesso de demandas ou tensão de longa duração, gerando sobrecarga à mulher.

A partir das falas das interlocutoras identifica-se a fragilidade estrutural da rede social de apoio no que concerne a pequena quantidade de pessoas identificadas como fonte de apoio; alto nível de densidade entre a mãe-criança e baixo entre os demais membros da rede; a dificuldade de acesso às pessoas para divisão das atribuições e as características socioculturais predominantes, fortalecendo os papéis impostos historicamente.

\begin{tabular}{l|l|l|l|l|l}
\hline Serv. Soc. \& Saúde & Campinas, SP & v. 19 & $1-20$ & e020005 & e-ISSN 2446-5992 \\
\hline
\end{tabular}




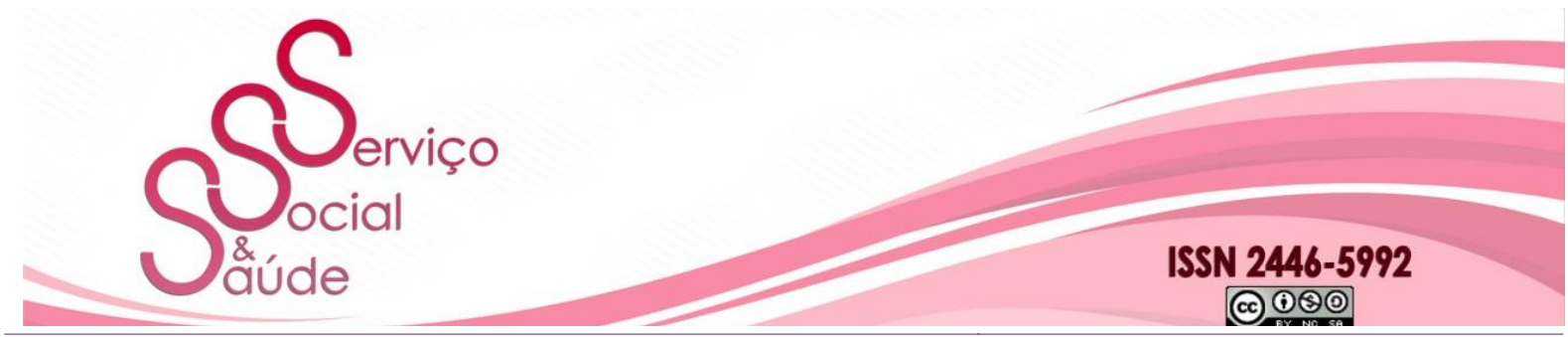

doi: 10.20396/sss.v19i0.8661082

\subsection{A importância da família no processo de cuidado}

Entendendo que a família apresenta significativa influência sobre a qualidade das relações intrafamiliares, buscou-se compreender a visão das entrevistadas sobre a família e sua importância durante esse percurso, com isso, foram feitas algumas perguntas para se chegar ao objetivo da pesquisa, como: "Qual a importância da família durante a hospitalização da criança?" e “O que é família para você?” As falas das entrevistadas fortalecem o discurso da família como primordial e de grande valia para elas e para a criança hospitalizada.

Acho que a família é importante, né? O apoio pra criança... Claro, como mãe eu tenho que tá presente, mas a mãe também precisa de um apoio porque esse momento é muito difícil, até porque eu acabei de sair de um parto, né? Tá muito recente, eu descobri a cardiopatia dela muito cedo, com quatro semanas de gestação, então não foi uma gestação tranquila. Então, quando ela nasceu, eu fiz questão de tá presente e até porque eu acho que ninguém vai cuidar tão bem quanto eu, eu faço questão de ficar. Família pra mim é a base de tudo, sem família a gente não vai pra frente, família é muito importante. (E4)

Ajuda bastante, né? Ajuda muito... Porque assim, até pro bem dele, pra melhoria do quadro. Quando a família tá perto, você se sente mais seguro. Então melhora bastante, tudo melhora quando a família tá perto. [...] Tudo, tudo... tudo mesmo! (E5)

Eles moram longe, aí só sou eu mesmo e Deus. O pai dele veio só uma vez depois do transplante. [...] Família é quem dar apoio, as coisas que a gente precisar, principalmente assim... doença, né? Precisa mais da família. (E7)

Eu acho que tanto pra ele, quanto pra mim, o suporte, de saber que eu posso contar com outras pessoas da família é primordial. A gente se sente sozinha e a carga se torna bem mais difícil, bem mais pesada. Contando com o apoio da sua família, você se sente bem mais fortalecido pra enfrentar a luta aqui, porque o negócio não é fácil, não. [...] Minha família é tudo, eu acho que família é a base de tudo, porto seguro, onde você se sente acolhido. (E8) 


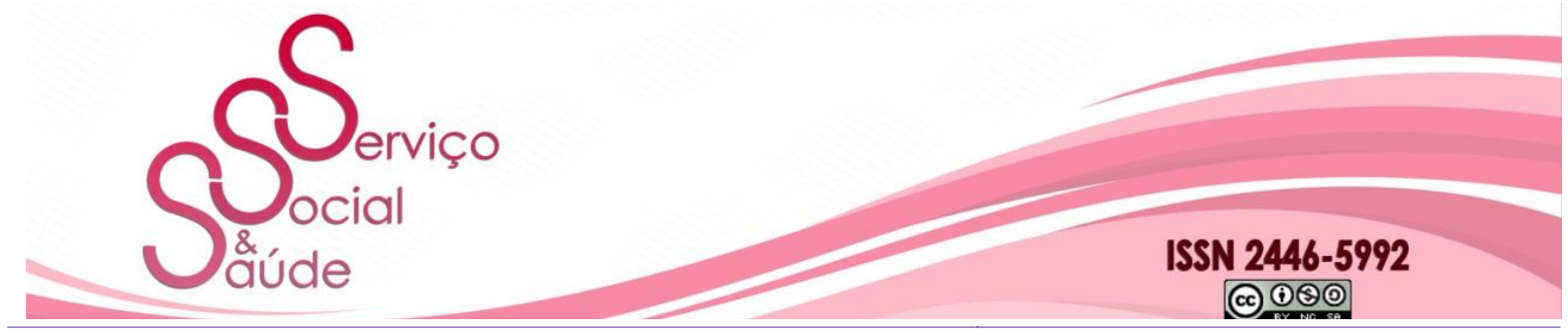

doi: $10.20396 /$ sss.v19i0.8661082

As características da relação família e doente/cuidador são pouco citadas nos estudos que visam a relação da influência da família durante o processo de hospitalização da criança, porém, esses foram os momentos em que as acompanhantes mais discorreram sobre a temática. Cabe aqui a importância de enaltecer as falas das interlocutoras da pesquisa, visto que os discursos mostram a experiência vivenciada por estas.

Analisando as falas, percebe-se que as mulheres sentem a necessidade do apoio da família e compreendem a sua importância e influência que exerce. Porém, apesar de reforçarem a necessidade do apoio da família e relatarem que esta é a sua "base", "porto seguro", foi observado alguns discursos contraditórios, pois mesmo as participantes compreendendo a família como essencial durante a hospitalização da criança e sendo considerada seu "suporte", a maioria das entrevistadas passam por esse processo de internação sem apoio familiar, ou seja, estão apenas trazendo conceitos de família desvinculados com o que estas vivenciam em suas realidades.

\section{CONSIDERAÇÕES FINAIS}

Apesar das mudanças ocorridas no âmbito da família, esta ainda é considerada como "base" para o ser humano, e permanece em muitas famílias o modelo padrão, mononuclear, constituído por mãe, pai e filhos, ainda que a realidade mostre inúmeras configurações de outros arranjos. Tendo isso em vista, a partir do estudo buscou-se compreender sua participação no cenário hospitalar. Com esta pesquisa, constatou-se que a família, no geral, não participa de forma efetiva do cuidado com a criança hospitalizada, ficando apenas uma pessoa responsável pelo seu cuidado, a mãe, e na sua ausência, geralmente, quem assume esse papel na família é outra mulher, pois, historicamente, o cuidado é delegado à figura feminina.

É nítida a manutenção dos papéis tradicionais de mães cuidadoras, figuras centrais no cuidado do filho(a) hospitalizado, aumentando a carga de compromisso e atividades destinadas ao cuidar. Percebe-se a permanência do contexto sócio-histórico e cultural que deposita na condição materna toda a responsabilidade do cuidado no campo familiar, quando 


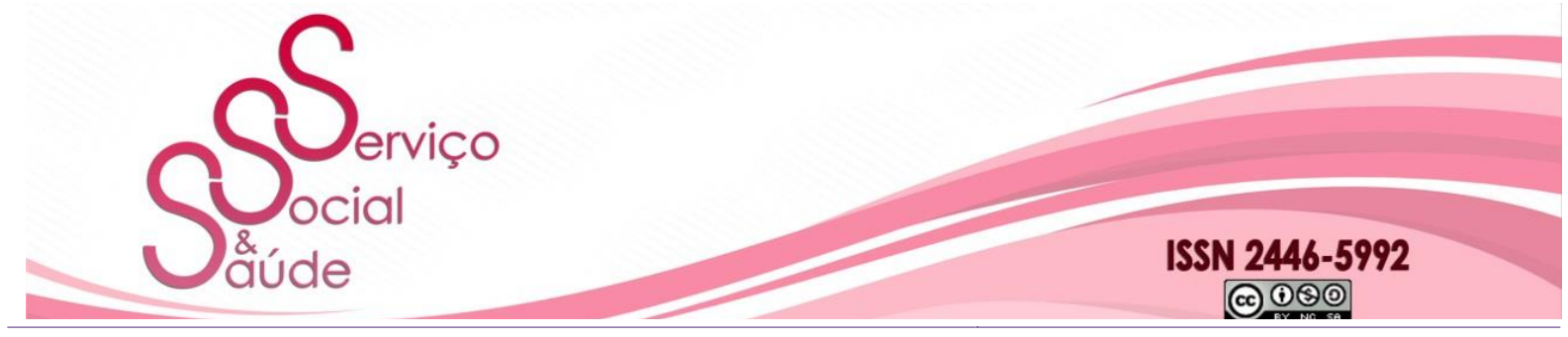

doi: 10.20396/sss.v19i0.8661082

se sabe da necessidade e importância de dividir papéis/funções com os pais, já que a responsabilidade os cabe também.

Os relatos das entrevistadas mostram a dificuldade que as mulheres enfrentam por exercerem a maternidade em tempo integral. Para manter o cuidado com a criança, a grande maioria das participantes da pesquisa saíram do mercado de trabalho e se dedicam exclusivamente ao filho(a), se considerando totalmente responsável por este, devido à sua própria criação, em que foi estabelecido como papel da mulher o ato de cuidar.

Assim, é importante salientar que as mulheres cuidadoras necessitam de atenção do Estado, da sociedade e principalmente da família, pois estão inseridas em um contexto complexo, que afeta sua saúde física e mental e as adoecem. Torna-se necessário a criação de políticas e ações que questionem tais papéis impostos e possam criar novas possibilidades, fortalecendo e ampliando a autonomia feminina e a clareza do cuidado como atribuição de todos os indivíduos sociais.

Recebido em março de 2020 - Aprovado em julho de 2020

\section{REFERÊNCIAS}

ALVES, J. P.; Costa L. H. R. Mães que cuidam de filhos (as) com necessidades especiais em perspectiva de gênero. Revista Eletrônica Gestão \& Saúde Vol. 05, No. 03, Ano 2014; p.796-807.

ANJOS, C. O familiar acompanhante da criança e a equipe de enfermagem no centro de terapia intensiva pediátrico oncológico: um espaço de interação no cuidado de enfermagem. Dissertação (Mestrado em Ciências do Cuidado) - Universidade Federal Fluminense. Rio de Janeiro, 2015.

BARROS, A.; LEHFELD, N. Fundamentos da metodologia científica. São Paulo: Makron Books.2000. 


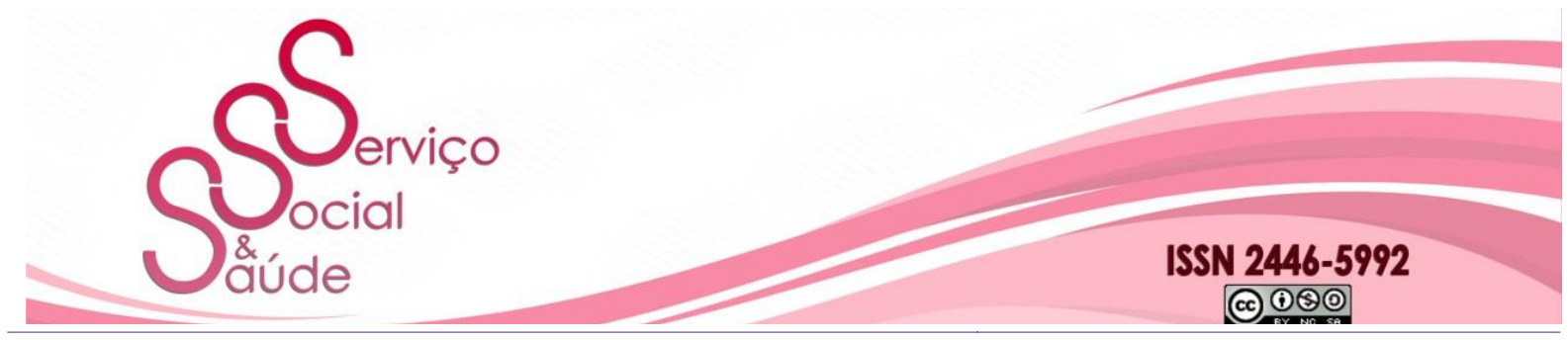

doi: 10.20396/sss.v19i0.8661082

BRASIL. Lei n. 8.069, de 13 de julho de 1990. Dispõe sobre o Estatuto da Criança e do Adolescente e dá outras providências. Diário Oficial [da] República Federativa do Brasil, Brasília, DF, 16 jul. 1990. Disponível em:

http://www.planalto.gov.br/ccivil_03/LEIS/L8069.htm\#art266.

ESCOLA DE SAÚDE PÚBLICA DO CEARÁ. Manual do Profissional Residente.

Informações ético-político-pedagógicas sobre a residência integrada em saúde - RIS-ESP/CE Fortaleza, Ceará, 2019.

FAIRHURST, G.; PUTNAM, L. L. Organizações como construções discursivas, 2001.

GAÍVA, M. A. M.; SCOCHI, C. G. S. A participação da família no cuidado ao prematuro em UTI Neonatal. Revista Brasileira de Enfermagem, 2005. Disponível em:

<http://www.scielo.br/pdf/reben/v58n4/a12v58n4.pdf $>$.

GIL, A. C. Entrevista. In: Métodos e Técnicas de Pesquisa Social. 6. ed. SãoPaulo: Atlas, 2008. Disponível em https://ayanrafael.files.wordpress.com/2011/08/gil-a-c-mc3a9todos-etc3a9cnicas-de-pesquisa-social.pdf.

GUEDES, O.S.; DAROS M.A. O cuidado como atribuição feminina: contribuições para um debate ético. Serviço Social em Revista, Londrina, V. 12, N.1, 122 P. 122-134, J. 2009. JORGE, A. Família e hospitalização da Criança - (Re) Pensar o Cuidado em Enfermagem. Loures: Lusociência. 2004

JOSÉ FILHO, P. M. Pesquisa: contornos no processo educativo. In: JOSÉ FILHO, P. M; DALBÉRIO, O. (org.). Desafios da pesquisa. Franca: UNESP - FHDSS, 2006. p.63-75.

MAFRA, S. C. T. A tarefa do cuidar e as expectativas sociais diante de um envelhecimento demográfico: a importância de ressignificar o papel da família. Revista Brasileira de Geriatria e Gerontologia. Rio de Janeiro, v. 14, n. 2, 2011. p. 353- 363.

Disponível em: http://revista.unati.uerj.br/scielo.php?script=sci_arttex\&pid=S1809$98232011000200015 \& \operatorname{lng}=$ pt.

MELO,E. M. O. P. et al. Envolvimento dos pais nos cuidados de saúde de crianças hospitalizadas.Revista Latino-Americana de Enfermagem [periódico na internet] 2014. Disponível em:

\begin{tabular}{l|l|l|l|l|l}
\hline Serv. Soc. \& Saúde & Campinas, SP & v. 19 & $1-20$ & e020005 & e-ISSN 2446-5992
\end{tabular}




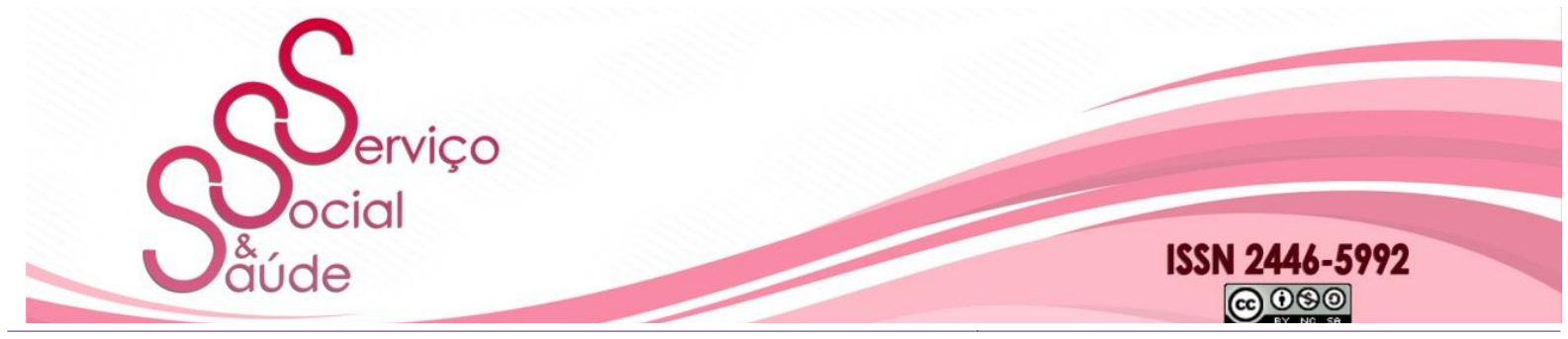

doi: 10.20396/sss.v19i0.8661082

http://www.scielo.br/pdf/rlae/v22n3/pt 0104-1169-rlae-22-03-00432.pdf.

MINAYO, M. C. S. O desafio do conhecimento: pesquisa qualitativa em saúde. 14a edição. São Paulo: HUCITEC, 2014.

MINAYO, M. C. S. Pesquisa social: teoria, método e criatividade. 34a edição. Petrópolis:

Editora Vozes Limitada, 2015.

MIOTO, R. C. Família; trabalho com família e Serviço Social. Serviço Social em Revista, Londrina, v. 12, n. 2, p. 163-176, jan./jun. 2010. Disponível em:

<http://dx.doi.org/10.5433/1679-4842.2010v12n2p163>.

ONG OXFAM.Tempo de cuidar. ONU Mulheres, 2020. Disponível

em:http://www.onumulheres.org.br/noticias/novo-relatorio-da-onu-mulheres-apresenta-umaagenda-politica-para-acabar-com-a-desigualdade-de-genero-nas-familias/.

PUTNAM, L L.; FAIRHURST, GT (2001). Discourse analysis in organizations. In JABLIN, F. M.; PUTNAM, L. L. (Eds.). The new handbook of organizational communication (p. 78-136). Thousand Oaks, CA: Sage Publications, 2001.

SILVEIRA, A. O. et al. Rede de apoio social familiar e a promoção do desenvolvimento infantil. Revista Família, Ciclos de Vida e Saúde no Contexto Social,vol. 04, n. 1,2016, p. 6-16. disponível em:

http://seer.uftm.edu.br/revistaeletronica/index.php/refacs/article/view/1528/1319 